\title{
0 trabalho nas instituições de Educação Superior
}

\author{
Work in Higher Education institutions \\ El trabajo en instituciones de Educación Superior
}

\section{DEISE MANCEBO \\ JOÃO DOS REIS SILVA JÚNIOR \\ DENISE BESSA LÉDA}

\begin{abstract}
O}$ texto discute o trabalho nas instituições de educação superior (IES). É um estudo de caráter exploratório e sua construção apoia-se em pesquisa bibliográfica e documental de temáticas necessárias para a compreensão da questão. Preliminarmente, contextualiza o tema no processo mundial de reestruturação produtiva em curso no país. Segue-se breve análise da diversificação do trabalho nas IES brasileiras, com especial destaque ao trabalho terceirizado. Por fim, discute a terceirização e conclui, analisando seus principais impactos para os trabalhadores e para as instituições públicas.
\end{abstract}

Keywords: Trabalho; terceirização; Educação Superior.

Resumo: The text discusses the work in higher education institutions (IES). It is an exploratory study. Bibliographic and documentary research supports its construction, using necessary themes for understanding the question. Preliminarily, it contextualizes the subject in the process of global productive restructuring underway in the country. Then, there is a brief analysis of the diversification of work in Brazilian IES, with special emphasis on outsourced work. Finally, it discusses the outsourcing and concludes by analyzing its main impacts on workers and public institutions.

Palavras-chave: Work; outsourcing; Higher Education.

Resumen: El texto discute el trabajo en las instituciones de educación superior (IES). Es un estudio de carácter exploratorio y su construcción se apoya en investigación bibliográfica y documental de temas necesarios para la comprensión de la cuestión. Preliminarmente, se contextualiza el tema en el proceso mundial de reestructuración productiva en marcha en el país. Se sigue con un breve análisis de la diversificación del trabajo en las IES brasileñas, con especial énfasis en el trabajo subcontratado. Finalmente, se discute la subcontratación y se concluye, analizando sus principales impactos sobre los trabajadores y las instituciones públicas.

Palabras clave: Trabajo; subcontratación; Educación Superior. 


\section{INTRODUÇÃO}

O objetivo do presente texto é oferecer uma melhor intelecção da problemática, que pode ser assim enunciada: quem é o trabalhador da universidade hoje?

Preliminarmente, pretende-se discutir a questão contextualizando-a no monumental processo de reestruturação produtiva desencadeado desde os inícios dos anos 1970 nos países centrais, e especialmente desde meados dos anos 1980, nos países do sul. É sabido que essas mudanças ocorridas no capitalismo recente foram de grande intensidade e desencadearam um conjunto de transformações, alterando profundamente o trabalho e a própria constituição e forma de ser da classe trabalhadora.

No Brasil, com o avanço das políticas neoliberais a partir de 1990, esse processo ampliou-se mediante a introdução de novas tecnologias, a adoção de padrões organizacionais e formas de organização do trabalho, com técnicas inspiradas no toyotismo, nas formas flexíveis de acumulação, bem como através do uso de amplo instrumental, que, no limite, burla a própria legislação social do trabalho. Como destacado por Antunes (2014): “A articulação complexa existente entre financeirização da economia, neoliberalismo, reestruturação produtiva e as mutações no espaço microcósmico do trabalho [e das instituições] não poderia deixar de afetar profundamente a classe trabalhadora” (p. 41).

Obviamente, as instituições de Educação Superior e o trabalho nelas desenvolvido não passaram incólumes a todo esse processo. Os impactos dessas mutações para o trabalho docente já é alvo de muitas discussões e investigações, o que não tem ocorrido em relação aos demais trabalhadores das IES, justificando, portanto, o presente trabalho.

$\mathrm{Na}$ sequência, o texto apresenta a seguinte estrutura: contextualiza o tema no processo de reestruturação produtiva em curso no país; segue-se breve análise da diversificação do trabalho nas IES brasileiras, com especial destaque ao trabalho terceirizado e, ao final, a própria temática da terceirização é analisada, dando vazão às conclusões que apontam para seus principais impactos para os trabalhadores e para as instituições públicas.

\section{O MUNDO DO TRABALHO NO CAPITALISMO CONTEMPORÂNEO}

O capitalismo contemporâneo - na busca por superar uma conjuntura de crise de outro padrão de desenvolvimento capitalista, marcado pelo fordismo 
e por um regime de regulação cuja experiência mais completa se deu nos países que conseguiram implementar um Estado de Bem-Estar - adota o regime de acumulação flexível.

$\mathrm{Na}$ realidade, pode-se dizer que o padrão de acumulação flexível articula um conjunto de elementos de continuidade e descontinuidade, que acabam por conformar algo relativamente novo e bastante distinto do padrão taylorista/ fordista de acumulação, gerando outro modo de trabalho e de vida, pautado na flexibilização e na precarização, "como exigências do processo de financeirização da economia, que viabilizaram a mundialização do capital num grau nunca antes alcançado". (DRUCK, 2015, p. 42).

As transformações no capitalismo contemporâneo resultaram, portanto, em um novo padrão de acumulação mundial que permitiu a livre circulação dos capitais em escala planetária. Chesnais (1996) denomina esse processo que se consumou nas últimas décadas, mundialização do capital, que, sob a égide dos Estados Unidos, resulta num modo de funcionamento específico do capitalismo, predominantemente financeiro e rentista. Essa evolução da esfera financeira impacta todos os demais empreendimentos do capital, subordinando a esfera produtiva e os modos de gestão do trabalho, forçando inclusive uma nova configuração do Estado, que "Passa a desempenhar um papel cada vez mais de 'gestor dos negócios da burguesia', já que ele age agora em defesa da desregulamentação dos mercados, especialmente o financeiro e o de trabalho". (DRUCK, 2015, p. 42).

Além disso, a hegemonia do setor financeiro ultrapassa o terreno estritamente econômico do mercado e impregna todos os âmbitos da vida social, dando conteúdo a um novo modo não só de trabalho, mas também de vida. A rapidez do tempo social, cunhada por Harvey (1994) de compressão temporal, incrementa a volatilidade, a efemeridade e a descartabilidade sem limites de praticamente todas as searas da vida, em especial, a da produção e do trabalho. É na busca da aceleração do ciclo do capital que se localiza a premência da flexibilização e da precarização do trabalho.

O curto prazo - como elemento central dos investimentos financeiros - impõe processos ágeis de produção e de trabalho, e, para tal, é indispensável contar com trabalhadores que se submetam a quaisquer condições para atender ao novo ritmo e às rápidas mudanças. Assim, a mesma lógica que incentiva a permanente inovação no campo da tecnologia e dos novos produtos financeiros, atinge a força de trabalho de forma impiedosa, transformando rapidamente os homens que trabalham em obsoletos e descartáveis, que devem ser "superados" e substituídos por outros "novos" e "modernos", isto é, flexíveis. (DRUCK, 2015, p. 42). 
Por ocasião da mais recente crise global, a partir de 2007-2008, esse quadro foi aprofundado, de modo que se pode verificar uma corrosão ainda maior do trabalho estável e regulamentado, próprio da matriz taylorianofordista, dominante ao longo do século XX e vem sendo substituída pelos mais distintos e diversificados modos de informalidade e precarização, na ânsia em ampliar os mecanismos de extração do sobretrabalho em tempo cada vez menor. Indiscutivelmente, assiste-se a uma explosão de novas modalidades de trabalho na indústria, na agricultura e nos serviços, que, de uma maneira geral, são mais precarizadas, permitindo-nos afirmar que a precarização social do trabalho está no centro da dinâmica do capitalismo flexível, combinando avanços tecnológicos com redução e precarização da força de trabalho.

No que diz respeito ao desenvolvimento tecnológico e suas repercussões no âmbito da precarização do trabalho, Dejours (2004) comenta:

\begin{abstract}
De um lado, a evolução tecnológica gera dificuldades que não estavam previstas, ou cuja previsão era insuficiente, acarretando novos riscos, desde a exposição à radiação ionizante até a jornada de trabalho em horários não usuais; de outro, desenvolvemse novas formas de gestão da mão-de-obra, com a utilização cada vez maior da terceirização de serviços, de trabalho temporário, de todas as formas de trabalho precário, o que leva a uma grande desestruturação das trajetórias profissionais e um golpe "invisível" na saúde (p. 303).
\end{abstract}

E é desse modo que no lócus onde se processam as relações de compra e venda da força de trabalho, qual seja, no plano do mercado de trabalho, os contratos, salários, as jornadas e as várias formas de inserção expressam um recrudescimento da mercantilização:

O capital reafirma a força de trabalho como mercadoria, subordinando os trabalhadores a uma lógica em que a flexibilidade, o descarte e a superfluidade são fatores determinantes para um grau de instabilidade e insegurança no trabalho, como nunca antes alcançado. (ANTUNES; DRUCK, 2014, p.17).

Na gestão e organização do processo de trabalho, a acumulação flexível, inspirada no toyotismo, emprega a reengenharia, adota a lógica da empresa enxuta, elimina postos de trabalho, força o aumento da produtividade e faz uso, sobremodo, da terceirização da força de trabalho. Assim, num contexto em que a economia, hegemonizada pela lógica financeira, sustenta o curtíssimo prazo, empresas do setor industrial e também a área de serviços buscam garantir altos rendimentos, cada vez em prazos mais curtos, "Exigindo e transferindo aos trabalhadores a pressão pela maximização do tempo, pelas altas taxas de produtividade, pela redução dos custos com o trabalho e pela 'volatilidade' nas formas de inserção e de contratos". (DRUCK, 2011, p.49). 
O conteúdo dessa nova precarização está garantido pela condição de instabilidade e de insegurança que a situação de forte desemprego produz, bem como pelas diversas formas de adaptabilidade e de fragmentação dos coletivos de trabalhadores no interior dos locais de trabalho. A terceirização, que aprofundaremos mais adiante, corresponde, como nenhuma outra modalidade de gestão, a essas exigências!

\section{O TRABALHO NAS INSTITUIÇÕES DE EDUCAÇÃO SUPERIOR NO BRASIL}

Comecemos pelos números. Em 1995, período de forte redução nos empregos formalizados, éramos 379.730 trabalhadores em atividade nas instituições de ensino superior (IES), incluindo técnicos (218.085) e funções docentes (161.645). Até 2014, foram criados 431.392 postos de trabalho, chegando-se a 811.122 trabalhadores, entre docentes (396.595) e técnicos (414.527). (BRASIL, 2016). Tivemos, portanto, um crescimento de 114\% em 19 anos, o que é muita coisa, especialmente, considerando-se a agressiva introdução da tecnologia (que, muitas vezes, economiza contratações), tentativas de enxugamentos de quadros e carreiras, incentivos à aposentadoria etc. Todavia, esses números não nos dizem muito, especialmente porque neles não são contabilizados os terceirizados, os bolsistas que trabalham em muitas instituições e os tutores do ensino a distância (EAD), por exemplo. Assim, para além dos números deve-se atestar outros aspectos sobre a complexidade do trabalho nas IES.

Uma primeira questão se refere a uma profunda diversificação existente nesse campo, a despeito de todos as ações (pela democratização e pela defesa de um padrão único de qualidade) que os movimentos de seus trabalhadores têm travado.

Atualmente, pode-se assistir, além da diversificação dos tipos institucionais, a diversificação das modalidades terminais (diplomas e certificados), de cursos e programas nas diferentes modalidades (presenciais, a distância, semipresenciais); a institucionalização de novos tipos de IES, como é o caso dos Institutos Federais de Educação Ciência e Tecnologia (IFs), criados em 2008; a diversificação e diferenciação, ainda, no tocante à adoção de formatos e modalidades diferentes na organização institucional e acadêmica, com cursos de ensino superior que visam a formar profissionais para atender a campos específicos do mercado de trabalho, com formatos compactos e duração média menor que a dos cursos de graduação tradicionais (sequenciais, por exemplo); assim como os cursos superiores com formatos de bacharelados e licenciaturas interdisciplinares que pecam pela abrangência na formação inicial (primeiro ciclo), calcados no princípio 
da flexibilização dos currículos; tendências de internacionalização da Educação Superior, dentre outras possibilidades.

\begin{abstract}
Em síntese, ocorre toda uma nova tendência, já designada oficialmente como educação terciária - termo proposto pelo Banco Mundial, em título de 2003 que confunde, não raramente, a educação superior com ensino pós-secundário, compreendendo: tutorias remotas, encurtamento de carreiras, flexibilização de currículos, importação de modelos educativos baseados na "aquisição de competências profissionais", certifi $\neg$ cação de saberes e destrezas, reciclagem de competências. Mesmo a designação do trabalho do professor, propriamente dito vem sendo transmutado de trabalho docente para "facilitador", "animador", "tutor" e "monitor", dentro outras novidades. (MANCEBO, 2010, p. 42).
\end{abstract}

Obviamente, a diferenciação não é neutra e remete, dentre outros aspectos, à forte hierarquização entre instituições, departamentos, egressos e também ao trabalho desenvolvido nos diversos espaços. O trabalho nas universidades públicas é exemplar quanto ao que se está afirmando. Em muitas delas, é possível encontrar núcleos de excelência, laboratórios de referência, carreiras do futuro, institutos do milênio, grupos de pesquisa internacionalizados, coexistindo com unidades ou departamentos onde os equipamentos estão deteriorados, os recursos são escassos, há alunos frustrados, professores extenuados e desprestigiados e técnicos assoberbados de tarefas. Enquanto as agências de fomento canalizam recursos para uns poucos cursos de pós-graduação de reconhecida qualidade (dentro do padrão de qualidade estabelecido pela CAPES), por exemplo, as graduações e as licenciaturas, muitas vezes vinculadas às mesmas faculdades e de qualidade também reconhecida, não encontram verbas para seus projetos. Contudo, mesmo tais graduações e licenciaturas veem-se submetidas às exigências de bom desempenho nas avaliações e ranqueamentos estabelecidos, que desconsideram as condições objetivas e subjetivas de realização do trabalho acadêmico.

Adicionalmente, deve-se relevar que a economia que emerge no póssegunda guerra mundial produz historicamente demandas para a indústria, especialmente para as corporações no âmbito mundial, exigências estruturais que têm requerido uma diminuição de tempo entre a produção científica e sua aplicação em serviços, produtos e processos. A ciência, básica ou aplicada (produzida no Brasil, basicamente nas universidades públicas), tem aí uma pressão para mudança, sendo necessário um novo tipo de conhecimento que atenda tais demandas, postas não mais por parâmetros exclusivamente científicos, mas, também, pela financeirização da economia. A economia converte-se, pois, no principal fator para a epistemologia da nova ciência acadêmica.

O conhecimento exigido pelas novas corporações ou grupos predominantemente industriais, tem entre suas redes de trabalho uma ou mais 
parcerias com universidades no mundo todo, que se dão de diversas formas, estrategicamente por meio de transferência de tecnologia e pela venda de direitos autorais pelas próprias universidades, como se pode observar no caso de pesquisas realizadas por algumas universidades estatais brasileiras. O conhecimento, na maioria das vezes, é transferido na forma de inovações sociais e tecnológicas e é o tipo de conhecimento que se pode denominar conhecimento "matéria-prima", termo que tem inspiração, especialmente na leitura dos trabalhos de Sheila Slaughter e Gary Rhoades (2010).

O conhecimento matéria-prima voltado para a economia e para o mercado é uma parte dos resultados da ciência em seu novo paradigma. Trata-se de conhecimento pronto para ser transformado em produtos de alta tecnologia, novos processos de produção e serviços e está relacionado à possibilidade de lucros imediatos no âmbito econômico. Tal dinâmica remete-nos, então, à inovação tecnológica: processo, ao mesmo tempo, de mudança, invenção e adaptação, que tem como objetivo agregar mais valor aos produtos no menor tempo possível.

Até há bem pouco tempo, o grande problema do capital consistia em diminuir o gap entre a ciência e a tecnologia e, embora houvesse uma aproximação entre a universidade e a indústria, ocorria, porém, uma considerável demora na solução dos problemas. Os intelectuais das indústrias estavam distantes dos processos de pesquisa e os pesquisadores, ávidos na defesa da autonomia de sua pauta de pesquisa, permaneciam distantes do front industrial e econômico. Contudo, com a predominância financeira, esse quadro se altera de forma radical. Ocorre que o ciclo de capital portador de juros faz dinheiro sem trabalho. $\mathrm{Na}$ equação marxista, temos D' > D. O proprietário do dinheiro investe, empresta e recebe os juros como forma de pagamento dessa operação pela mera propriedade privada do dinheiro. Essa operação, além de econômica, é jurídica e impõe as taxas de juros e o tempo de pagamento do que é devido, desconsiderando o que irá ocorrer no processo de produção real de valor. É uma aposta com o menor risco e a maior rentabilidade. Trata-se de uma abstração real que move a economia mundial e muda as instituições republicanas.

Esta operação pode ser feita entre amigos, empresas, grupo de empresas, países e pelos principais agentes institucionais que atuam mundialmente, que são os fundos mutuais, os guias da gestão do sistema monetário mundial, aos quais se subordinam os fundos de pensão e os fundos dos grupos predominantemente industriais, o que caracteriza um regime de predominância financeira. Quais as consequências disso?

Juridicamente, o ciclo financeiro comprime não só o ciclo do capital em funções (as relações sociais de produção), como também as relações sociais em geral, altera a sociabilidade e subjetividade de todo cidadão e exige a produção 
de valor real em tempo recorde do trabalho vivo. Nesse ponto, a instituição republicana universitária e a pesquisa nela produzida cumprem papel estratégico. Como? Redefinindo a ciência e o conhecimento, conforme a referida necessidade. Por essa via, a racionalidade econômico-financeira se interpõe nas práticas cotidianas da vida universitária.

Por outro lado, a organização e a gestão universitárias, mediante a reforma do aparelho do Estado, alteram-se de forma estrutural, trazendo para o centro da identidade institucional a racionalidade econômica. Isso está na raiz das explicações das reformas universitárias, no financiamento das universidades, na sua organização e gestão, na avaliação, na importância dos rankingss, na necessidade da expansão e da internacionalização da Educação Superior, em nova divisão internacional do trabalho científico, no acesso e no conhecimento que é produzido nessas instituições.

A observação do trabalho em curso nas IES brasileiras leva-nos, então, à constatação de uma profunda complexidade e diversidade, a começar pelo próprio trabalho docente. Temos, numa ponta, o professor-pesquisador que " $\mathrm{Na}$ distopia da universidade neoliberal, [...] deve se submeter a um conjunto determinado de rotinas intelectuais no menor tempo possível". (BIANCHI; BRAGA, 2015, p. 2), como discutimos, mas que, normalmente, desfruta de boas condições de trabalho e, em algumas circunstâncias, até de vencimentos adicionais como é o caso dos docentes que recebem bolsas e tendem a naturalizar a corrida solitária pelos editais. E, no outro extremo, o docente que utiliza seus próprios recursos para imprimir alguma qualidade e dignidade ao seu trabalho. Essa dicotomia tende a gerar, de forma velada ou aberta, uma distinção entre professores de primeira linha, que gozam de maior prestígio acadêmico, e professores de segunda linha, com menor prestígio e sofrendo todas as consequências daí decorrentes.

Por fim, sob o manto do Estado reformado, cuja lógica é a drástica redução da participação na esfera pública, os cortes das verbas para manutenção e renovação das IES são cada vez mais recorrentes, de modo que a infraestrutura física é abandonada. Todavia, o expediente mais francamente utilizado, possivelmente o mais importante, é o da redução do custo da própria força de trabalho através da implementação de uma variedade de estratégias de flexibilização/precarização que transformam as relações de trabalho e reduzem a folha de pagamento. E é neste campo que ocorre, por exemplo, a terceirização da força de trabalho auxiliar - em serviços com baixa remuneração, como o de zeladores, auxiliares de escritório, trabalhadores da cantina, jardineiros, pessoal de limpeza e seguranças etc. - para empresas que negam aos funcionários direitos trabalhistas básicos e proteção. (BURAWOY, 2015). 


\section{A TERCEIRIZAÇÃO E A NOVA GESTÃO DA FORÇA DE TRABALHO}

A terceirização frequentemente é apresentada, pela mídia tradicional, por empresários e até por alguns intelectuais, como uma moderna técnica de organização e gestão da produção, que traz maleabilidade às empresas, processo imprescindível para a saúde destas e, portanto, de uso irreversível diante do mundo competitivo atual.

Todavia, sob outra vertente, a terceirização não é tão inédita e benéfica assim. De fato, a técnica da terceirização não advém da recente reestruturação produtiva conhecida como toyotismo, mas se trata, em verdade, de uma recauchutagem de instrumento que data do início da própria Revolução Industrial, em fins do século XVIII e início do século XIX. Sob a argumentação de Carelli (2015, s.p.), a terceirização

\footnotetext{
É historicamente conhecida sob o nome de "putting-out system" a exploração de trabalhadores para realizar parte da produção dos capitalistas em seus próprios domicílios, o que transformou artesãos independentes em trabalhadores empobrecidos e limitados. Esse tipo de "terceirização", com a entrega de parte da produção para ser realizada externamente e de forma complementar ao realizado dentro dos muros da fábrica, aconteceu principalmente nos setores da confecção e da indústria bélica na Inglaterra. (p. ).
}

Do mesmo modo, pode-se citar que o fenômeno da intermediação de mão de obra também tem suas raízes já antigas. Não é, de forma alguma, algo recente, sendo seus efeitos perversos há muito tempo conhecidos e reconhecidos em todo o mundo. Em 1848, só para citar um famoso exemplo, na França, durante a revolta que culminou na revolução popular desse mesmo ano, "Uma das principais manifestações da população era justamente contra os intermediários entre o 'empresário' e os trabalhadores, tendo sido verificado o caráter odioso do lucro pela mera venda do trabalho alheio" (CARELLI, 2015).

O que é novo e digno de nota é seu retorno, em amplíssima escala, sendo sua aplicação instrumento central no contexto da reestruturação produtiva ocorrida a partir do final dos anos 1970. A terceirização tem sido estratégia de largo e polêmico uso no capitalismo contemporâneo, dentro do contexto da nova ofensiva do capital, com a vigência do capitalismo flexível. Disseminou-se na indústria, agricultura, comércio e serviços, no setor privado, mas também no setor público, incluindo a administração pública, "Alterando não apenas a morfologia social do trabalho, mas o sociometabolismo laboral no Brasil", como comenta Alves (2014). 
Deve-se destacar que muitas organizações (como é o caso das IES) fazem uso da terceirização não porque estejam buscando uma especialização técnica externa, que pudesse incrementar a produtividade, mas sim, com o objetivo de racionalizar gastos e, no caso do setor privado, visando ao aumento de seus lucros, em especial através do pagamento de baixíssimos salários, da imposição de extensas jornadas, como mínimo de investimento nas condições de trabalho. Assim, pode-se definir a terceirização como "Todo o processo de contratação de trabalhadores por empresa interposta, cujo objetivo último é a redução de custos com a força de trabalho e/ou a externalização dos conflitos trabalhistas" (MARCELINO, 2013, p. 50).

No Brasil, a partir da década de 1990, a terceirização se constituiu na principal forma de flexibilização da contratação. Conforme Antunes e Druck (2014), trata-se de uma “verdadeira epidemia", generalizando-se, progressivamente, não só para as chamadas atividades-meio, mas também para as atividades-fim e utilizando-se de novas modalidades de contratação, como cooperativas, empresas pejotizadas e trabalho em domicílio, também chamado de teletrabalho.

Pesquisas já realizadas em diversos setores revelam que, além do crescimento da terceirização, ocorrem múltiplas formas de precarização dos trabalhadores terceirizados em todas essas atividades: nos tipos de contrato, na remuneração, nas condições de trabalho e saúde e na representação sindical.

É sabido que não há estatísticas precisas sobre a terceirização no Brasil, dada a dificuldade de captá-las nas empresas. Porém, o Dieese e a CUT (2014) registraram que, em 2014, os setores "tipicamente terceirizados" correspondiam a 26,8\% dos empregos formais no Brasil. Nesse mesmo estudo, um conjunto de indicadores revelam as desigualdades entre trabalhadores terceirizados e os demais: a remuneração dos empregados em setores tipicamente terceirizados é 24,5\% menor do que a dos demais empregados; a jornada de trabalho dos terceirizados é de três horas a mais semanalmente, sem considerar horas extras ou banco de horas realizadas, que não são objeto do levantamento do MTE (Ministério do Trabalho e Emprego) - outra limitação das estatísticas oficiais brasileiras. O tempo de emprego demonstra uma diferença ainda maior entre trabalhadores diretos e terceiros. Enquanto a permanência no trabalho é de 5,8 anos para os trabalhadores diretos, em média, para os terceiros é de 2,7 anos. Esse fato decorre da alta rotatividade dos terceirizados - 64,4\% contra 33\% dos diretamente contratados. Esse último aspecto acarreta uma série de consequências para o trabalhador terceirizado, que alterna períodos de trabalho e períodos de desemprego, resultando na falta de condições para organizar e planejar sua vida, inclusive para projetos pessoais como sua própria qualificação. (DIEESE; CUT, 2014). 
No caso do serviço público, ao longo da década de 1980, pode-se atestar que o número de terceirizados era muito pequeno e praticamente inexistente dentro das universidades e demais IES. Nas décadas seguintes, esse número aumentou significativamente, evoluindo para uma situação onde há muitos trabalhadores frequentemente sem vínculo empregatício e sem registro formalizado, por vezes à margem da legislação trabalhista.

A expansão da terceirização no serviço público tem alguns marcos importantes, sendo os principais: os programas de privatização de empresas e de serviços públicos implementados a partir dos anos 1990 e a reforma do Estado iniciada em 1995, por meio do Plano Diretor da Reforma do Aparelho do Estado, de responsabilidade do Ministério da Administração Federal e Reforma do Estado (Mare), que estimula a extinção de cargos funcionais, dentro da lógica do enxugamento do aparelho do Estado. Simultaneamente, foi definida uma legislação que fomentou a terceirização. Primeiramente, o Decreto-Lei $n^{\circ}$ 2.271, de 7 de julho de 1997 (BRASIL 1997) ampliou as atividades terceirizáveis e definiu aquelas que deveriam ser contratadas de forma indireta. Em seguida, tivemos a Lei de Responsabilidade Fiscal (LRF), ou Lei Complementar $n^{\circ} 101$, de 4 de maio de 2000 (BRASIL, 2000), que fixou um limite de gastos do governo com pessoal do quadro do serviço público, mas que não computou os contratos de prestação de serviços, isto é, a contratação de terceirizados. Em outros termos, esta legislação inibiu a realização de concursos públicos e incentivou a terceirização, pois as despesas com a subcontratação de empresas, a contratação temporária, emergencial e de comissionados não são computadas como pessoal. Conforme Druck (2015), com isso, uma mudança de fundo se operou, por exemplo, nos orçamentos das universidades federais e um número crescente de servidores foi deslocado da verba de pessoal para a de custeio, na condição de terceirizados. Adicionalmente, criou-se e se ampliou a diversidade de modalidades de terceirização na esfera pública, a exemplo de:

Concessão, permissão, parcerias, cooperativas, ONGs, Organizações Sociais e as Organizações da Sociedade Civil de Interesse Público. Um quadro em que parte dos serviços públicos é realizada não mais pelo "servidor público", profissional concursado, mas pelos mais diferentes tipos de trabalhadores, em geral empregados de forma precária, com contratos por tempo determinado, por projetos, sem os mesmos direitos que o funcionário público e com salários mais baixos. (DRUCK, 2015, s.p.) 
No contexto atual, para agravar esse quadro, empresários e governos querem derrubar qualquer limite à terceirização. Para tal, retomaram o Projeto de Lei (PL) no 4.330 de 26 de outubro de 2004', que libera a terceirização, ampliando sua aplicação para as chamadas “atividades-fim”. Esse Projeto foi aprovado em 22 de abril de 2015 na Câmara de Deputados e ainda está em andamento no Senado Federal, como Projeto de Lei da Câmara (PLC) 30/2015.

A justificativa "nobre" para o PL seria a de "proteger" os trabalhadores terceirizados e, ao mesmo tempo, dar segurança jurídica e competividade às empresas. Todavia, o Projeto vem sendo apontado, por trabalhadores e centrais sindicais, como uma tentativa de desmonte radical dos direitos básicos consagrados na Constituição Federal e na vasta legislação trabalhista que as lutas sociais produziram no último século. Ele visa, de fato, retirar qualquer barreira jurídica à contratação de "prestadores de serviços", os quais poderiam exercer funções relativas a atividades "inerentes, acessórias ou complementares" à atividade econômica da contratante, ou seja, nas chamadas atividades-meio e atividades-fim, termos criados pela jurisprudência em vigor. Assim, o Projeto de Lei no 4.330 (BRASIL, 2004) enfraquece os direitos sociais, ofende a Constituição, acentua a concentração de riqueza e produz injustiça.

Originalmente, o Projeto fazia menção às empresas públicas, às sociedades de economia mista e suas subsidiárias e controladas, no âmbito da União, dos estados, do Distrito Federal e dos municípios (Art. $1^{\circ} ; § 1^{\circ} \mathrm{I}$ ). Todavia, por pressão dos movimentos ligados a esse setor, uma emenda supressiva retirou a aplicação do PL a administração pública direta. Por certo, foi uma vitória dos movimentos; no entanto, os ataques efetuam-se por todos os lados! E não é por coincidência que uma semana antes da votação do PL, precisamente no dia 15 de abril de 2015, sem muito alarde, estava sendo julgada no Supremo Tribunal Federal a Ação Direta de Inconstitucionalidade (ADI)n ${ }^{\circ}$ 1923, que trata exatamente da possibilidade de transpasse, pelo administrador, de serviços públicos ao setor privado. Conforme Souto Maior (2015, s.p.):

O que o Supremo disse, [...] em 2015, é que a atuação do Estado na saúde, na educação, na cultura, no desporto e lazer, na ciência e tecnologia e no meio ambiente pode se realizar mediante uma gestão compartilhada com o setor privado, por intermédio da formalização de "instrumentos de colaboração público/privada", pelos quais se reserva a participação do Estado como entidade de "fomento", não

\footnotetext{
1 O Projeto de Lei 4330/2004 é de autoria do deputado Sandro Mabel, empresário do setor de alimentação, que propõe a liberação total da terceirização para todas as atividades (fim e meio), em redes de subcontratação, sem responsabilidade solidária das empresas contratantes. Dentre outras proposições, o Projeto, tal como aprovado na Câmara, também diminui a "quarentena" de pessoas que saiam de um trabalho e passem a prestar serviço como terceirizado. Pela proposta, o funcionário pode voltar à empresa como terceirizado após 12 meses e não 24 como estava previsto, até então.
} 
apenas com transferência de recursos financeiros, mas também pela cessão de bens públicos e até de servidores públicos, sendo que esses instrumentos, que são, de fato e de direito, convênios, serão feitos com ONGs, alçadas ao "status" "título jurídico") de Organização Social por meio de deliberação do próprio ente público.

Pelo exposto, havia - e ainda há - uma gama de interesses para a ampliação da terceirização no setor público, que se pretende seja implementada sem debate com a opinião pública a respeito.

Fato é que a terceirização exerce forte impacto sobre o mundo do trabalho. Por certo, todo trabalhador está sujeito à precarização e a não ver respeitados seus direitos, mas a terceirização potencializa essa tendência e não é difícil de se imaginar o que pode acontecer quando esse processo vier a se expandir para um grande número da população economicamente ativa. É uma alteração que quebra a ideia de um padrão mínimo equânime e igualitário para a força de trabalho regulamentada e permite a desregulamentação ampliada da classe que vive do trabalho.

O par terceirização/precarização é inseparável, por seu caráter desagregador e degradante desse processo, no que diz respeito ao salário, às condições de trabalho, à preservação da saúde e, também, sobre a organização sindical. A condição de desempregado ou a ameaça permanente da perda do emprego, por exemplo, traz efeitos particularmente graves, não apenas para a saúde física e psíquica do trabalhador, como tem-se constituído, adicionalmente, numa eficiente estratégia de dominação no âmbito do trabalho. Como observado por Druck (2011):

[O isolamento e a perda de enraizamento, de vínculos, de inserção, de uma perspectiva de identidade coletiva, resultantes da descartabilidade, da desvalorização e da exclusão, são condições que afetam decisivamente a solidariedade de classe, solapando-a pela brutal concorrência que se desencadeia entre os próprios trabalhadores. (p.50).

Para além do acirramento da concorrência, ocorre um esfumaçamento do autorreconhecimento e do reconhecimento dos laços coletivos, fruto da desvalorização simbólica e real, que tem condenado cada trabalhador a ser o único responsável por sua empregabilidade e sua vida, submetendo-se pacificamente a diversos níveis de sofrimento, inclusive justificando-o para se manter empregado e, tudo isso, em uma conjuntura extremamente adversa criada pelo capitalismo flexível. Mas a terceirização contribuiu para romper os laços de solidariedade não somente por essas razões interpessoais - o que já seria suficiente. A terceirização contribui fortemente para fragilizar e desunificar a representação sindical, pois cria uma variedade de atores, sindicatos e trabalhadores, com interesses diversos 
- não raro divergentes - que impõe limites objetivos à luta coletiva. Como bem sintetizaram Antunes e Druck (2014):

\begin{abstract}
No que se refere ao coletivo de trabalhadores, a terceirização fragmenta, divide, aparta, desmembra as identidades coletivas, individualiza e cria concorrência entre os que trabalham muitas vezes no mesmo local, nas mesmas funções, mas que estão separados de fato e simbolicamente pelo crachá diferente e pelos diferentes uniformes, que identificam os de primeira e segunda categoria. (p. 18).
\end{abstract}

Por fim, um efeito colateral desse processo, mas nada desprezível, é que a terceirização abre espaço para relações promíscuas entre instituições públicas e empresas privadas que disputarão os contratos de prestação de serviços, agravando, consequentemente, a corrupção.

\title{
CONSIDERAÇÕES FINAIS: A TERCEIRIZAÇÃO NAS UNIVERSIDADES PÚBLICAS
}

As mudanças que vêm ocorrendo no âmbito do trabalho alcançam toda seara onde ele é realizado e todas instituições em que a produção de valor é operada, como se pôde ver no texto até então. Mesmo que consideremos as especificidades, as transformações no mundo do trabalho têm-se encaminhado numa mesma direção: a perda dos direitos sociais do trabalho e sua respectiva intensificação, que diminuem o custo da mercadoria força de trabalho. No que se refere à terceirização presente nas universidades brasileiras, vale destacar que ela é parte desse processo mais amplo. Isso posto, deve-se atentar para o fato de que as universidades públicas vêm experimentando muitos problemas com o uso da terceirização em variadas frentes!

Como já registrado, o custo com esses trabalhadores foi deslocado, progressivamente, da verba de pessoal para a de custeio. Isto porque muitos cargos foram extintos nos novos planos de carreira das IES, constituindo hoje o conjunto dos terceirizados. Consequentemente, na estrutura administrativa de diversas IES, esses trabalhadores acabam ficando sob a responsabilidade da área de finanças, de contratos; em síntese, são alocados na área administrativa, e não nos setores responsáveis pelo pessoal, como os demais trabalhadores da universidade.

Para os terceirizados, são recorrentes, entre outros, atrasos de valetransporte, de vale-alimentação, o não pagamento de $13^{\circ}$ e de férias, o não fornecimento de equipamentos de proteção e até o não-pagamento de salários. As empresas contratadas pelo menor preço, conforme a lei de licitações, não possuem, 
em geral, situação financeira estável, e para garantir seu preço, economizam na força de trabalho, no pagamento dos direitos e dos salários dos trabalhadores.

As greves (ou movimentos pontuais de paralização) de trabalhadores terceirizados, especialmente nos serviços de vigilância e limpeza, têm sido momentos importantes para a análise da situação, pois é nessas circunstâncias que esses trabalhadores se tornam visíveis para as instituições e para a própria sociedade. A falta de limpeza e ou de vigilância, por óbvio, inviabiliza a prestação de qualquer serviço público, seja na educação ou na saúde, levando à paralização dessas instituições, demonstrando o quanto são essenciais e que, portanto, deveriam fazer parte do corpo do funcionalismo, como ocorria em passado recente. (SANTANA; DRUCK, 2015).

Mesmo com a terceirização das "atividades-meio" deixando explícitos os graves problemas que ela provoca para os trabalhadores e para as IES, há sinalizações claras de que as "atividades-fim" podem ser consideradas em mais uma rodada de terceirizações. Caminhamos assim para uma agudização do processo de precarização, vivido (já há longas datas) na docência da Educação Superior através das figuras do professor horista, professor substituto e, mais recentemente, dos tutores de EaD.

Como analisamos no corpo desse texto, o ano de 2015 trouxe um conjunto de questões ao debate público brasileiro acerca do tema, quando o Supremo Tribunal Federal (STF), no dia 16 de abril, tomou uma medida legitimadora sobre o repasse da gestão de diversas áreas da administração pública, inclusive a educação, às Organizações Sociais (OS) - entidades privadas sem fins lucrativos, como associações e fundações privadas.

Assim, no caso das IES públicas, dependendo da interpretação, já está liberada a contratação de qualquer trabalhador, inclusive docentes, por meio de OS (ONGs, fundações, cooperativas etc.). Os docentes, por exemplo, já podem ser contratados como prestadores de serviços para dar aulas, por tempo determinado, para uma disciplina ou um curso, sem qualquer vínculo com a vida universitária e sem poder contribuir com a pesquisa e a extensão. Se hoje os contratos de professores substitutos, temporários e tutores do ensino a distância já expressam a precarização, "A contratação de professores via OS, sem concursos públicos e sem direitos, amplificará o grau de precarização existente, colocando em xeque o papel do docente na educação pública superior". (SANTANA; DRUCK, 2015, p. 57).

Em síntese, está montado um cenário sombrio, que tende a aprofundarse em tempos de regime de exceção, no qual a degradação e a precarização do trabalho, que, nas IES, já ocorre pela terceirização das chamadas "atividadesmeio" poderá somar-se à das "atividades-fim"! 


\section{REFERÊNCIAS}

ALVES, Giovanni. Terceirização e neodesenvolvimentismo no Brasil. Disponível em:https://blogdaboitempo.com.br/2014/08/11/terceirizacao-eneodesenvolvimentismo-no-brasil/. Acesso em: 22 set. 2015.

ANTUNES, Ricardo. Desenhando a nova morfologia do trabalho no Brasil. Estudos Avançados, v. 28, n. 81, p. 39-53, 2014.

; DRUCK, Graça. A epidemia da terceirização. In: ANTUNES, Ricardo (Org.). Riqueza e miséria do trabalho no Brasil III. São Paulo: Boitempo, 2014. p. 13-24.

BIANCHI, Álvaro; BRAGA, Ruy. Um conto de duas universidades: quando a lógica mercantil se sobrepõe à construção do pensamento crítico e reflexivo. Revista Cult. Disponível em: http://revistacult.uol.com.br/home/2010/03/ umcontodeduasuniversidades/. Acesso em: 22 set. 2015.

BRASIL. Sinopses estatísticas do Censo da Educação Superior: 19952015. Brasília: MEC. Disponível em: <http://www.inep.gov.br/superior/ censosuperior/sinopse/ default.asp >. Acesso em: 10 fev. 2016.

Projeto de Lei $\mathbf{n}^{\mathbf{0}} \mathbf{4 . 3 3 0}$, de 26 de outubro de 2004. Dispõe sobre os contratos de terceirização e as relações de trabalho deles decorrentes. Disponível em: http://www.camara.gov.br/proposicoesWeb/fichadetramitacao?idProposic ao $=267841$. Acesso em: 5 maio 2016.

Lei Complementar $\mathbf{n}^{\mathbf{0}} \mathbf{1 0 1}$, de 4 de maio de 2000. Estabelece normas de finanças públicas voltadas para a responsabilidade na gestão fiscal e dá outras providências. Disponível em: http://www.planalto.gov.br/ccivil_03/leis/LCP/ Lcp101.htm. Acesso em: 5 maio 2016.

Decreto-Lei n $\mathbf{n}^{\mathbf{2}}$ 2.271, de 7 de julho de 1997. Dispõe sobre a contratação de serviços pela Administração Pública Federal direta, autárquica e fundacional e dá outras providências. Disponível em: http://www.planalto.gov.br/ccivil_03/ decreto/d2271.htm. Acesso em: 29 ago. 2016.

BURAWOY, Michael. Ensino superior em crise: o contexto global. Margem Esquerda: ensaios marxistas, São Paulo, n. 25, p. 43-51, out. 2015. 
CARELLI, Rodrigo de Lacerda. A terceirização no século XXI. Disponível em: https://blogdaboitempo.com.br/2015/04/01/a-terceirizacao-no-seculo-xxi/. Acesso em: 29 ago. 2016.

CHESNAIS, François. A mundialização do capital. São Paulo: Xamã, 1996.

DIEESE; CUT. Terceirização e desenvolvimento: uma conta que não fecha. São Paulo: Central Única dos Trabalhadores, 2014.

DEJOURS, Christophe. Entre sofrimento e reapropriação: O sentido do trabalho. In: LANCMAN, Selma; SZNELMAR, Laerte (Orgs.). Christophe Dejours: da psicopatologia à psicodinâmica do trabalho. Rio de Janeiro/Brasília: Fiocruz/ Paralelo 15, 2004. p.303-316.

DRUCK, Graça. A terceirização no setor público e a proposta de liberalização da terceirização pelo PL 4330. Disponível em: https://blogdaboitempo.com. br/2015/04/01/a-terceirizacao-no-setor-publico-e-a-proposta-de-liberalizacaoda-terceirizacao-pelo-pl-4330/. Acesso em: 29 ago. 2016.

Trabalho, precarização e resistências: novos e velhos desafios? Caderno CRH, Salvador, v. 24, n. 01, p. 37-57, 2011.

HARVEY, D. Condição pós-moderna. São Paulo: Edições Loyola, 1994.

MANCEBO, Deise. Diversificação do ensino superior no Brasil e qualidade acadêmico-crítica. In: OLIVEIRA, João Ferreira de; CATANI, Afrânio Mendes; SILVA JÚNIOR, João dos Reis. (orgs.). Educação superior no Brasil: tempos de internacionalização. 1ed. São Paulo: Xamã, 2010. p. 37-53.

MARCELINO, Paula. Trabalhadores terceirizados e luta sindical. Curitiba: Appris, 2013.

SANTANA, Marco Aurélio; DRUCK, Maria da Graça. Terceirização e degradação do trabalho nas universidades brasileiras. Margem Esquerda: ensaios marxistas, São Paulo, n. 25, p. 52-57, out. 2015.

SLAUGHTER, Sheila; RHOADES, Gary. Markets in Higher Education. In: ALTBACH, Philip G.; GUMPORT, Patricia J.; BERDAHL, Robert O. (Eds.). 
American Higher Education in twenty-first century - social, political and economic challenges. 3.ed. Baltimore: The John Hopkins University Press, 2010. p. 433-464.

SOUTO MAIOR, Jorge Luiz. ADI 1923: legitimação e ampliação da terceirização no setor público. Carta Maior, 22 de abril de 2015. Disponível em http://cartamaior.com.br/?/Editoria/Principios-Fundamentais/ADI-1923legitimacao-e-ampliacao-da-terceirizacao-no-setor-publico/40/33321. Acesso em: 29 ago. 2016.

DEISE MANCEBO é doutora em Educação (História e Filosofia da Educação) pela Pontifícia Universidade Católica de São Paulo (1995), com pós-doutorado pela Universidade de São Paulo. É professora titular da Universidade do Estado do Rio de Janeiro. Desenvolve suas principais atividades no Programa de Políticas Públicas e Formação Humana (PPFH), do qual foi fundadora e membro da coordenação de 2006 a 2012. Foi coordenadora do Gt Políticas de Educação Superior da ANPED (2000 a 2004), bem como coordenadora do Conselho Científico da mesma entidade (2006-2008). Participa da rede Universitas/Br, desde sua criação e é sua coordenadora desde 2016. É líder do Grupo de Pesquisa do CNPQ (Trabalho docente na educação superior) e coordena o Observatório da Educação (CAPES) sobre a Expansão da educação superior no Brasil. Tem experiência na área de Psicologia e Educação, pesquisando, principalmente, os seguintes temas: trabalho docente; políticas para a educação superior e produção de subjetividades. E-mail: deise.mancebo@gmail.com

JOÃO DOS REIS SILVA JÚNIOR é doutor em Educação: História, Política, Sociedade pela Pontifícia Universidade Católica de São Paulo (PUC/SP). Pósdoutorado em Sociologia Política pela Universidade de Campinas (UNICAMP); em Economia pela Universidade de São Paulo (USP) e em Economia pela Universidade de Londres. Professor associado da Universidade Federal de São Carlos (UFSCar). Visiting Professor na Mercer University (GA-US-2012-2014) e na Arizona State University (2014-2015). Livre-docente pela Universidade de São Paulo (USP). Pesquisador da Rede Universitas/Br e Coordenador adjunto do Observatório da Educação (OBEDUC) "Políticas da Expansão da Educação Superior no Brasil”. E-mail: joaodosreissilvajr@gmail.com

DENISE BESSA LÉDA é doutora em Psicologia Social pela Universidade do Estado do Rio de Janeiro (2009). É professora nível Associado II da Universidade Federal do Maranhão (UFMA). Professora permanente do Programa de PósGraduação em Psicologia da UFMA. Líder do Grupo de pesquisa "Sociedade contemporânea, mundo do trabalho e processos de subjetividade". Integra a coordenação colegiada do Grupo de pesquisa "História, Sociedade e Educação no Brasil” (HISTEDBR) no Maranhão. Participa da Rede Universitas/Br; do GT 11 - "Política de Educação Superior", da Associação Nacional de Pósgraduação e Pesquisa em Educação (ANPED) e do GT "Psicodinâmica e Clínica 
do trabalho" da Associação Nacional de Pesquisa e Pós-graduação em Psicologia (ANPEPP). Desenvolve pesquisa integrada sobre a expansão da educação superior, no âmbito do Observatório da educação superior (OBEDUC/ CAPES). Principais temas de pesquisa: mundo do trabalho; trabalho docente e educação superior. E-mail: denisebl@uol.com.br

Recebido em setembro de 2016

Aprovado em outubro de 2016 